\title{
Equity, Anti-Racism and Social Justice: Mission Statements, Vision and Values of British Columbia's Health Delivery System
}

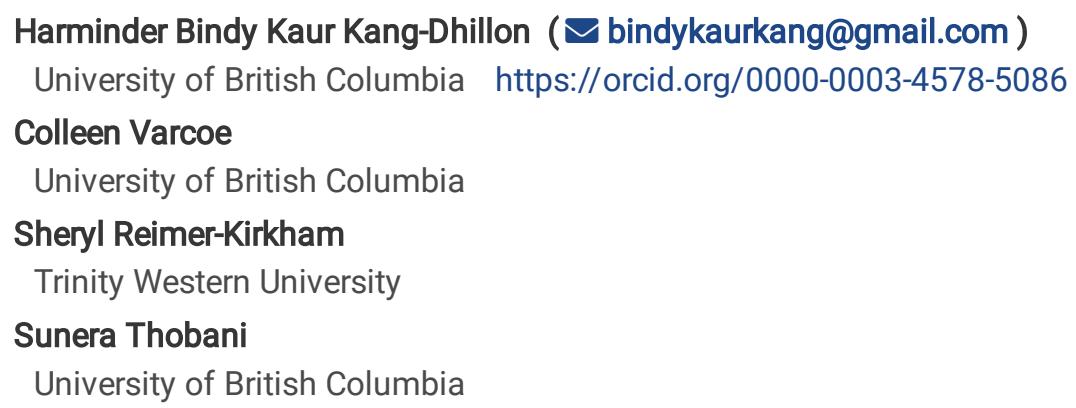

\section{Research}

Keywords: Equity, Anti-Racism, Diversity, Universal Healthcare, Organizational Statements, Canada

Posted Date: May 29th, 2020

DOl: https://doi.org/10.21203/rs.3.rs-27646/v1

License: (c) (i) This work is licensed under a Creative Commons Attribution 4.0 International License. Read Full License 


\section{Abstract \\ Background}

Framed by a universal healthcare philosophy, publically funded Canadian healthcare delivery organizations are presumed to provide primary care for all residents. However, despite this universal coverage, healthcare inequity is evidenced for non-dominant racialized patients and healthcare providers.

\section{Methods}

To examine the diversity commitments of healthcare delivery organizations in British Columbia, we analyzed mission statements, visions and values with a list of 23 health equity markers.

\section{Results}

Our findings reveal that health equity for racialized non-dominant communities is not prioritized in the mission, vision or value statements for 7 of the 8 healthcare delivery organizations.

\section{Conclusion}

The absence of these markers reaffirms that anti-racist ideologies are not conceptualized into the institutional identities of British Columbia's healthcare delivery organizations. Further, without an anti-racism equity framework embedded into institutional identity, organizations have a limited ability to meaningfully address inequities experienced by racialized non-dominant patients and healthcare providers. We recommend that healthcare delivery organizations review and revise their guiding documents with a lens of equity, social justice and cultural safety; and to incorporate education for all healthcare leadership and staff through the lens of antiracist pedagogy.

\section{Introduction}

"Words, whether spoken or written, do things ... Texts also circulate: they move around ... Words might get repeated and this repetition might increase or decrease their value depending on how they are received" (Ahmed, 2009)

Healthcare organizations convey their identity, purpose and commitment through specific institutional 'words' particularly the strategic triangle: mission statements, visions and values that ideally drive institutional decisions and policies. These institutional "words ... do things" - perform particular roles and functions (Ahmed, 2009), and portray the institutions' overall 'story': who they are, what they value and where they are going. Part of the institutional story of Canadian healthcare delivery organizations is that healthcare is a 'right' (Romanow, 2002) and as such, Canada has committed to universal healthcare coverage (Canada Health Act, 1984) to advance health equity (CSDH, 2008; United Nations, 2015). Further, the Canadian state embraces an inclusive diversity narrative with the adoption of the Multiculturalism Act that "[recognizes] and [promotes] ... the cultural and racial diversity of Canadian society and acknowledges the freedom of all members of Canadian society to preserve, enhance and share their cultural heritage" and "[promotes] the full and equitable participation of individuals and communities of all origins" with a commitment to "assist them in the elimination of any barrier to that participation" (Multiculturalism Act, 1985). In addition, as a signing member to the World Health Organization's constitution, Canada has committed to delivering the "highest attainable standard of health [as a] fundamental [right] of every human being ... without distinction of race, religion, political belief, economic or social condition"[1]. With landmark legislation (i.e. Canada Health Act (1984)[2] and the Multiculturalism Act (1985)[3]) and global health commitments, Canada embraces a necessary institutional framework intended to ensure equitable healthcare access and health outcomes for all Canadians; Yet, despite these philosophical commitments, legislation and considerable resources, health disparities persist. In this paper, we report the disjuncture between Canada's expressed national and global commitments and institutional realities with an analysis of mission statements, values and visions of healthcare delivery organizations in Canada's most western province of British Columbia. To foreground our findings, we provide a brief overview of health inequities; ideologies that underpin Canada's universal 
healthcare; describe the organizational significance of mission, vision and value statements; and present British Columbia's healthcare structure.

\section{Healthcare Inequities Persist Despite 'universal' Health Coverage}

Despite the provision of universal health care coverage, healthcare inequity is still evidenced in Canada (Frohlich, Ross \& Richmond, 2006; Kennedy \& Morgon, 2009; Schoen \& Doty, 2004; Lebrun, 2012). There is ample evidence to suggest that healthcare encounters between non-dominant racialized patients and healthcare providers include 'racial profiling' (Tator \& Henry, 2006; Henry, Tator, Mattis \& Rees, 1998) and other forms of racial bias, prejudice and stereotyping that result in health inequality (Tang \& Browne, 2008; Adelson, 2005; Frohlich, Ross \& Richmond, 2006; O'Neill \& O'Neill, 2008; Humphries \& van Doorslaer, 2006; Institute of Medicine, 2003; Pardies, Truong \& Priest, 2013; Paradies, Priest, Ben, Truong, Gupta, Pieterse, Kelaher \& Gee, 2013). These racially discriminatory interactions are not one directional but also experienced by racialized non-dominant healthcare providers in multiple ways, ranging from derogatory racial remarks (Ejaz, Rentscn, Noelkar \& Castora-Binkley, 2011; Kirkham, 2013) to being perceived as less competent than European Ancestry healthcare providers (Lo \& Bahar, 2013; DasGupta, 2009) and being purposefully excluded from work-related interactions, preferred work sites and promotions (DasGupta, 2009). As a system of power, racism permeates across the everyday movements and interactions of racialized non-dominant individuals stretching across social, cultural, political, economic and spiritual realities. Growing evidence highlights that when people experience inequities including racial discrimination, there is a direct cost to their well-being culminating in illnesses with diminished quality and quantity of life (Krieger, 2012; Schulz et al, 2006; Safaei, 2007; Sondik et al, 2010; Lukachko, Hatzenbuehler \& Keyes, 2014; Williams and Mohammed, 2008).

Collectively evaluated, the healthcare experiences of racialized non-dominant patients and healthcare providers narrate a pattern of marginalization and differential treatment; and for patients, this translates to differences in health outcomes. These inequities partly stem from the systemic race dynamics in which Canada, as a nation state, has been established and developed. Canada is founded in the violent and genocidal colonization of Indigenous Peoples which seeded ideologies of white supremacy, privilege and power that have continued to perpetuate denigrating individual, collective, political, cultural and societal racism towards Indigenous communities - culminating in denying Indigenous Peoples their personal and collective sovereignty (Maracle, 1996; Lawrence \& Dua, 2005; Alfred, 2009; Coulthard, 2014; Leon, Miller, Gabriel, Sparrow, Webb, Joe, Campbell, James, Planes, Underwood, Thomas \& McLeod, 2014). This racial hierarchy has also led to the inferior societal positioning of racialized non-European communities such that European ancestry Canadians (i.e. those who are perceived to be 'white') are elevated to the status of 'Exalted Subjects' (Thobani, 2007) and constructed as the 'true' citizens of Canada. Through rituals of questioning belonging (i.e. 'where are you really from'), asserting dominance ('why do they not speak English') and the classification of non-European ancestry Canadian citizens as 'visible minorities' (Thobani, 2007), racialized non-dominant Canadians are understood to be "politically minor players" - reinforcing that they are enduring 'outsiders' (Bannerji, 2000, p. 30). These historical and contemporary ideologies related to race reveal the longitudinal influence of Canada's 1867 founding aspiration to be a 'White Man's Country' (Dua, 2007, p. 446) (Kazimi, 2012) (Wallace, 2017) and contribute to contemporary systemic racism; which privileges dominant racialized communities, while comprehensively and actively subordinating non-dominant individuals and communities. Despite the progressive adoption of Multiculturalism and liberal ideologies, Canada continues to struggle with systemic inequities for racialized communities which translates to differences in quality of life and well-being (Pendakur \& Pendakur, 2002; Creese \&Wiebe, 2009; Pendakur \& Pendakur, 2011; Mikkonen \& Raphael, 2010; Ross, Garner, Bernier, Feeny, Kaplan, McFarland, Orpana \& Oderkirk, 2012; Bryant, Raphael, Shrecker \& Labonte, 2011; Pendakur \& Bevelander, 2014) and these ideologies serve as the foundational building blocks of Canadian institutions - including healthcare delivery organizations.

\section{Canada's Healthcare Vision and Diversity}

Canadians "consider equal and timely access to medically necessary health care services" as a basic need and a "right of citizenship, not a privilege of status or wealth" (Ramonow, 2002). Canadian Commissioner Roy J. Romanow's report: Building on Values: The Future of Health Care in Canada (2002) provided a poignant report on the Canadian health care system, and this report continues to be relevant today - 17 years later. Romanow's report emphasized the need for quality health care, defined as "delivering the best possible care and achieving the best possible outcomes for people every time they deal with the healthcare system or use its services" (Romanow, 2002, p. 150). 
For patients, high quality health care means that their needs and expectations are being met. For health care providers, quality health care means their diagnoses are accurate, they are part of a well-functioning system, and the care they provide is appropriate and effective. For our society as a whole, it means that the overall health of Canadians improves. (Romanow, 2002, p. 150)

Among the recommendations, the report identified that "governments, regional health authorities, and healthcare providers should continue their efforts" to "address the diverse health care needs of Canadians" (Ramanow, 2002, p. 150; recommendation 29, Romanow, 2002, p. 251). This use of 'diversity' explicitly includes gender, ethnicity/race, different abilities and newcomer status and plainly acknowledges that "Canada has a diverse population and that diversity should be reflected in Canada's health care system" (Romanow, 2002, p 155). The report also included input from direct care community organizations recommending that:

... health services should be more culturally sensitive, that health promotion materials should be written in more than the two official languages, and that health care professionals should reflect the diversity of Canadian society and understand the ethnic and cultural backgrounds of the populations they serve (Romanow, 2002, p. 156)

Romanow's call for cultural sensitivity and equal healthcare access continues to be relevant for racialized non-dominant British Columbians; particularly for healthcare delivery organizations in British Columbia as they serve an ethnically diverse patient population, mirroring the multicultural ethnic diversity across Canada. In response to an ethnically diverse population, British Columbia's healthcare delivery organizations have incorporated cultural competency training (Kang, Varcoe, Thobani and ReimerKirkham, in progress); diversity programs (Kang, Varcoe, Thobani and Reimer-Kirkham, in progress); extensive interpreter and translation services (Provincial Health Services Authority); and specific population programming (e.g. Fraser Health Authority's South Asian Health Institute, Vancouver Coastal Health's Aboriginal Wellness Program). The implementation of these policies and programs is often embedded in a culturist framework to explain differences or similarities between ethnic cultural groups (Johnson, Bottorff, Browne, Grewal, Hiliton \& Clarke, 2004). When policies and programs are designed based on culturist beliefs, healthcare access, treatment adherence and preventative lifestyle 'choices' are often linked to ethnic communities' lack of language fluency, cultural customs, beliefs and traditions - not the structure of our healthcare system, or the social, political and cultural context of our nation. However, with emerging Canadian research, critical health scholars continue to shed light on how systemic forms of racism play out in healthcare (Browne \& Varcoe, 2006; Varcoe, Browne, Wong \& Smye, 2009; Reimer Kirkham, 2003; Tang \& Browne, 2008; Adelson, 2005; Vukic, Jesty, Mathews \& Etowa, 2012) and highlight the impact of the social, cultural and political context in which British Columbia's healthcare delivery organizations are housed (Varcoe, 2006; Anderson and Reimer-Kirkham, 2002). Critical health researcher, Colleen Varcoe poignantly identifies that anti-racism and equitable praxis operates in the wider world within intersecting historical, social, political "racist context and broader racializing discourses" (Varcoe, 2006, p. 535). Further, critical health researchers extend calls for health equity to include how diversity policies and programs may inadvertently rely on culturist ideals that rely on "hegemonic systems of domination" and "further marginalize those they are intended to include" (Reimer-Kirkham \& Anderson, 2002, p. 252).

In summary, race based inequities persist in healthcare despite rhetoric promoting equity. Examining institutional discourse statements reveals how organizational commitments for health equity for non-dominant patients is absent or present in institutional identity. With a focus on British Columbia's health organizations, our research questions were: 1. How does the public institutional discourse (located in mission statements, values and vision) include diversity and health equity for racialized non-dominant patients, families and communities? 2. How are inclusion and equity discourses constructed in mission statements, values and vision? 3. What are the guiding 'truths' that inform these discourses? These analytical processes provide an in-depth analysis of all 8 healthcare organizations' guiding objectives and ideologies in regards to meeting health equity for racialized non-dominant communities.

\section{Why Focus On Mission, Vision And Value Statements?}

Mission, vision and value statements of healthcare delivery organizations narrate their organizational identity, objectives and values. As institutional discourse, the 'words' used in these statements convey the cultural, political and societal framework that support current day approaches, programs and initiatives to healthcare delivery in British Columbia, and incorporate strategic priorities set forth by British Columbia's Ministry of Health. Originally designed to promote a corporate organizations' "shared expectations amongst employees and communicate a public image ... to important stakeholders" (Analoui \& Karami, 2002), mission statements 
also define organizational purpose (Scandura et al, 1996) and goals (Toftoy \& Chatterjee, 2004); guide strategic plans (Palmer \& Short, 2008), leadership style (Analoui \& Karami, 2002) and staff recruitment (Baetz \& Bart, 1996); and communicate corporate identity (Leuthesser \& Kohli, 1997). In recent years, the nonprofit sector has adopted mission statements as a meaningful technique to communicate core values and activities to stakeholders (Kirk \& Nolan, 2010). Healthcare organizations have also embraced the usefulness of mission statements (Grbic, Hafferty \& Hafferty, 2013; Ramsey \& Miller, 2009; Bart \& Hupfer, 2004; Bart \& Tabone, 1998; Bolan, 2005) with an emphasis on identifying their purpose (i.e. improving public health), institutional identity, scope of practice, and strategic direction in the mission statement.

Along with the mission statement, many organizations including BC's healthcare delivery organizations include a vision and list of values. Organizational vision and values parley the institutions' core ideology and envisioned future (Collins \& Porras, 1991, 1997). The vision includes a clear and compelling long-term goal (Khalifa, 2012), a "future destination so strongly appealing that it inspires the wholehearted commitment of all relevant stakeholders" (Bart \& Hupfer, 2004, p. 101). The values identify "guiding principles and essential and enduring tenets" (Khalifa, 2012, p. 239) as well as communicate workplace ethic and culture - "attracting and building loyalty among individuals who share and honor the same ethos" (Bart \& Hupfer, 2004, p. 101). Collectively, organizational culture is confirmed through these types of institutional discourse statements to communicate "management beliefs, perspectives and approaches ... to employees and stakeholders [patients and families]" (Babnik, Breznik \& Dermol, 2013, p. 613) as well as share the broader cultural context: a "view of the physical, political and social environment in which an institution is embedded" (Grbic, Hafferty \& Hafferty, 2013, p. 852). Analyzing these institutional discourse statements offers an understanding of organizational culture and ethos that drives the delivery of British Columbia's 'universal' healthcare commitment and possible disjunctures from the principles of accessibility and universality that affirm "the conviction of Canadians that essential health care services must be available to all Canadians on the basis of need and need alone" (Romanow, 2002, p. 61).

\section{Project Context: British Columbia's Healthcare System}

Located on the Western coast of Canada, the province of British Columbia is home to approximately 4.4 million peopleand has a budget of 18.8 billion dollars to publically administer, comprehensive, universal, portable and accessible health care in accordance with the Canada Health Act (Canada Health Act, 1985). While British Columbia's Ministry of Health is responsible to "[ensure] that quality, appropriate, cost effective and timely health services are available for all British Columbians", five provincial health authorities (Fraser Health Authority, Interior Health Authority, Northern Health Authority, Vancouver Coastal Health Authority, and Vancouver Island Health Authority) provide direct health care delivery (Ministry of Health 2016/12-2018/19 Service Plan, February 2016). Additionally, the Provincial Health Services Authority collaborates with the 5 provincial health authorities to provide specialized province-wide health services such as cardiac and stroke services, oversees BC Ambulance Service and Patient Transfer Network, as well as operates specialized health centers (e.g. BC Children's Hospital and BC Cancer agencies). In coordination with the Ministry of Health, Vancouver Coastal Health Authority and Provincial Health Services Health Authority, Providence Health Care also operates in the Greater Vancouver Area to provide specialized care through 14 healthcare facilities inspired by 5 different congregations of Catholic Sisters. In many ways, Providence Health performs similarly to the other Health Authorities but receives horizontal governance and support from Vancouver Coastal Health (e.g. Vancouver Coastal Health's Aboriginal Wellness program supports Providence Health when needed). Further, the first province-wide health authority in Canada to focus on Canada's Indigenous patients, families and communities: the First Nations Health Authority is dedicated to improving the "health and wellbeing of BC's First Nations and Aboriginal people". It is important to note that their "work does not replace the role or services of the Ministry of Health and Regional Health Authorities" but instead FNHA "[collaborates], [coordinates], and [integrates] ... respective health programs and services to achieve better health outcomes for BC's First Nations".

Similar to other formalized, government-directed healthcare bodies, British Columbia's healthcare delivery organizations (HDOs) are structured institutions shaped by federal and provincial leadership, policies and mandates with multiple levels of governance and leadership (e.g. Board of Directors, Senior Leadership, Directors) and accountability platforms (e.g. report cards, strategic directions). Each healthcare delivery organization has a unique leadership team which designs the organizational processes and systems in response to federal and provincial mandates, specific direct care health delivery needs and patient populations. These guiding directives ideally would be reflected in institutional identity, purpose, core values, strategic direction and scope of care through publically shared institutional discourse (e.g. mission statements, values and visions). 


\section{Methods}

\section{Data Collection}

This paper draws on a broader qualitative study that has incorporated a Critical Ethnographic approach informed by Post/Colonial, Critical Race and Feminist theories. Focused on the Western province of British Columbia, we collected mission statements, values and visions identified by all eight of British Columbia's healthcare delivery organizations. All of the healthcare delivery organizations share their mission statements, values and visions publically on their websites. Screen shots were captured to maintain a record of the collected data. Data was organized into three groupings: 1. Mission statements; 2. Vision; and 3. Values.

\section{Data Analysis}

Each of the data groupings (mission statements, visions and values) were reviewed through several readings and reflective journaling to identify emerging themes. These themes were collaboratively discussed and followed with another set of readings to conduct thematic coding. Data was also read for specific words and phrases that would identify objectives, priorities and values regarding health equity for racialized non-dominant patients. The following words and phrases were identified as equity markers addressing health equity for racialized non-dominant communities: culture; traditions; ethnicity; race; cross cultural; cultural safety; cultural humility; cultural sensitivity; cultural competency; cultural proficiency; equity; diversity; inclusion; social justice; antioppression; anti-racism; racism; racialized; visible minority; hegemonic; dominant; power; and micro-aggressions. To finalize the analysis we read the data groupings to attend to the research questions outlined previously.

\section{Results}

\section{Mission Statements :}

British Columbia's healthcare delivery organizations offer a distinctive array of goals, sense of purpose and institutional identity through their mission statements. Not surprisingly, 'health' is a key theme that can be traced in all eight mission statements; and confirms their commitment to supporting healthy individuals and communities. Care, particularly the act of 'caring', is also identified as a central theme, albeit not explicitly expressed in all of the mission statements. For instance, Vancouver Coastal Health Authority explicitly identifies 'care': "We are committed to supporting healthy lives in healthy communities with our partners through care, education and research"; while others (e.g. Northern Health Authority) infer a caring paradigm: "Through the efforts of dedicated staff and physicians, in partnership with communities and organizations, we provide exceptional health services for Northerners". Only Providence Health identified 'compassionate care'. While 'care' offers positive opportunities for healthcare support, 'compassionate care' advances care to "sympathetic consciousness of others' distress ... with a desire to alleviate it" (Merriam-Webster Dictionary, 2019). Additional themes of Education and Research; Innovation; Quality and Safe Care were less prominent though still visible as a part of the organizational purpose.

Patient-Centered care was highlighted as the first priority in the BC Ministry of Health's Setting Priorities for BC Health Care report and tasked healthcare delivery organizations to commit to "[shift] the culture of health care from being disease-centred and providerfocused to being patient centred" $(2014$, p. 3). No health authority identified the word 'patient(s)' in their mission statements; however, many made reference to 'communities'. Providence Health uniquely refers to patients as "those served" while Northern Health Authority identifies "Northerners" as their service community. The First Nations Health Authority was the only healthcare delivery organization to explicitly identify "working with [people] on their health and wellness journeys". While many health authorities present patient-centred care as a part of their healthcare delivery model, the mission statements do not share this commitment to 'working with' patients but rather, mission statements articulate a 'providing for' model. Although, patients are essential in the healthcare encounter as they directly receive healthcare through these institutions, patient agency is almost absent in the mission statements. In response to British Columbia's Ministry of Health's priority, patient centered care is featured on the websites of Provincial Health Services Authority, Vancouver Coastal Health Authority, Fraser Health Authority, Providence Health, Vancouver Island Health Authority, Interior Health Authority and the First Nations Health Authority with explicit acknowledgment that patients and families are to be treated with respect and dignity and encouraged to collaborate with health care teams to be active in their healthcare journeys.

Another term commonly used to signal excellence in healthcare delivery is 'quality' as it is rooted in an ideology of delivering good healthcare. 'Quality' was frequently featured in the mission statements with Vancouver Island Health Authority's mission statement 
including: "to provide superior health care through ... a commitment to quality and safety"; while Interior Health Authority's mission statement: "provide needed health services ... to the highest professional and quality standards" (please see Table 1) includes both 'quality and 'safety'. Although, there is mention of 'quality' and 'safety' in these mission statements, it is unclear what is meant by 'quality' or 'safety'. To better understand this, we examined what was meant by 'patient care quality'. All of the healthcare delivery organizations included a Patient Care Quality office with the exception of the First Nations Health Authority (which does not directly provide direct care) with explanations on how to file complaints and share compliments but no definitions of what constitutes 'quality' or 'safety' - or identify why complaints would be filed. In 2008, the Patient Care Quality Review Board Act was introduced to address patient care quality complaints in "a clear, consistent, timely and transparent approach" in British Columbia. There is no clear definition of what constitutes 'patient care quality' in the Patient Care Quality Review Board Act but only that a 'care quality complaint' refers to "the delivery of, or the failure to deliver, health care; the quality of health care delivered; the delivery of, or the failure to deliver, a service relating to health care; [or] the quality of any service relating to health care". It remains unclear as to what would breach 'patient care quality' and 'safety'.

When we analyzed the mission statements for the twenty-two health equity markers for racialized non-dominant communities, we found only one mission statement to include 'culture' and 'traditions'. The placement of "honouring traditions and cultures" in the First Nations Health Authority's mission statement signals their institutional commitment to provide culturally safe care for Indigenous patients, families and communities in British Columbia; particularly relevant for Indigenous communities who face welldocumented health inequities on the unceded territories of present-day Canada. The health equity markers for racialized nondominant communities that are entirely absent from the mission statements are: ethnicity/race; cross cultural; cultural safety; cultural humility; cultural sensitivity; cultural competency; cultural proficiency; equity; diversity; inclusion; social justice; antioppression; anti-racism; racism; racialized; visible minority; hegemonic; dominant; power; and micro-aggressions. This absence indicates that there is a gap in acknowledging the necessity of culturally safe healthcare for all patients in British Columbia served by publically funded healthcare delivery organizations in a universal health delivery framework.

Table 1

British Columbia's Healthcare delivery organization Mission Statements

\section{PHSA Provincial health results through caring, leading and learning together}

VCHA We are committed to supporting healthy lives in healthy communities with our partners through care, education and research

$\mathrm{PH} \quad$ Inspired by the healing ministry of Jesus Christ, Providence Health Care is a Catholic health care community dedicated to meeting the physical, emotional, social and spiritual needs of those served through compassionate care, teaching and research.

VIHA To provide superior health care through innovation, teaching and research and a commitment to quality and safetycreating healthier, stronger communities and a better quality of life for those we touch.

FHA Purpose: To improve the health of the population and the quality of life of the people we serve

IHA Promote healthy lifestyles and provide needed health services in a timely, caring, and efficient manner, to the highest professional and quality standards.

NHA Through the efforts of dedicated staff and physicians, in partnership with communities and organizations, we provide exceptional health services for Northerners.

FNHA The FNHA supports BC First Nations individuals, families and communities to achieve and enjoy the highest level of health and wellness by: working with them on their health and wellness journeys; honouring traditions and cultures; and championing First Nations health and wellness within the FNHA organization and with all of our partners.

Vision

Institutional 'vision' defines an organization's aspirational long-term direction, practices and goals; in essence, 'vision' provides imagery of what the institution will be doing in the future. The reviewed vision statements appear to be comprised of honorable aspirations to provide the best in healthcare with terms such as 'best care', 'excellence in health', 'excellent care', 'better health', and 'exceptional care'; however, it is unclear how 'best', 'excellent' or 'better' are defined (please see Table 2). For instance, Vancouver Coastal Health Authority's vision is to be "leaders in promoting wellness and ensuring care by focusing on quality and innovation" 
through their four organizational goals of providing "best care", "promote better health", "develop the best workforce" and "innovate for sustainability". Not only are ideas of best and better ambiguous, but it is unclear as to how staff become "leaders in promoting wellness and ensuring care" or how they "develop the best workforce", or how they "promote better health", or how care is experienced by patients. While vision achievement is difficult to measure, these guiding institutional 'words' are constructed in ambiguous terms that remain vague, overarching end-goals that are challenging to assess for successful attainment. Further, 'patients' are an entirely absent word from the vision statements; albeit, Providence Health references "those served through compassionate care, teaching and research" which would ideally include patients; and the First Nations Health Authority identifies "working with" "BC First Nations individuals, families and communities".

In regards to the twenty-two health equity markers for racialized non-dominant communities, vision statements for Providence Health and First Nations Health Authority incorporated elements of a health equity framework. Providence Health's vision statement: "driven by compassion and social justice, we are at the forefront of exceptional care and innovation" explicitly identifies 'social justice' as a part of their long-term vision; thus includes an aspirational trajectory towards egalitarianism (Merriam-Webster Dictionary, 2017). The First Nations Health Authority's vision: "healthy, self-determining and vibrant BC First Nations children, families and communities" emphasizes a future whereby Indigenous communities are empowered and active in their holistic well-being. As a part of holistic well-being, this vision statement acknowledges a transformative shift from the current social and political standing of Indigenous Peoples as advocating for self-determination to a future position whereby Indigenous individuals and communities can have the fundamental right to be 'self-determining'. The health equity markers that are entirely absent from the vision statements are: ethnicity/race; cross cultural; cultural safety; cultural humility; cultural sensitivity; cultural competency; cultural proficiency; equity; diversity; inclusion; anti-oppression; anti-racism; racism; racialized; visible minority; hegemonic; dominant; power; and microaggressions.

Table 2

British Columbia's Healthcare delivery organization Vision Statements

\section{PHSA Province wide solutions for excellence in health, every time}

VCHA We will be leaders in promoting wellness and ensuring care by focusing on quality and innovation (with 4 organizational goals to achieve their vision: provide the best care; promote better health for our communities; develop the best workforce; and innovate for sustainability)

$\mathrm{PH} \quad$ Driven by compassion and social justice, we are at the forefront of exceptional care and innovation.

VIHA Excellent Care and Health for Everyone, Everywhere and Every time

FHA Better health. Best in healthcare.

IHA To set new standards of excellence in the delivery of health services in the Province of British Columbia.

NHA Northern Health leads the way in promoting health and providing health services for Northern and rural populations.

FNHA Healthy, Self-Determining and Vibrant BC First Nations Children, Families and Communities.

Values

Institutional values identify what is important to the institution, and ideally help guide institutional decisions. 'Respect' was the most identified 'value' with 7 health institutions including it in their value statements. While, the meaning of 'respect' varied slightly from "[treating] people as individuals with unique beliefs, values, lived experiences and cultural norms" (Provincial Health Services Authority, 2017) to "to [valuing] each individual and bring trust to every relationship" (Vancouver Island Health, 2017) - the overall sense of 'respect' was to honour the individual and their unique perspectives and experiences. In line with honouring 'uniqueness', respect also encompassed the terms: diversity and culture. Placing importance on 'diversity' was explicitly identified in three of the value statements. Value statements such as "to give the kind of care we would want for our loved ones" (Vancouver Island Health, 2017) and "[we] are courteous, and treat each other as valued clients and colleagues" (Interior Health Authority, 2017) infer compassionate healthcare encounters. Further, value statements defined what values meant for the organization. For example, 'trust' was described as "we behave in ways that promote safety, inclusion and support" (Table 3.3).

The First Nations Health Authority (FNHA) includes 'culture' as a value statement that acknowledges Indigenous ancestors and "[draws] upon the diverse and unique cultures, ceremonies, customs and teachings of First Nations for strength, wisdom and 
guidance" and affirmation that FNHA "[upholds] traditional and holistic approaches to health and self-care" (Table 3.8). In comparison to the other healthcare delivery organizations, the First Nations Health Authority offers the lengthiest descriptions of their value statements; explicitly defining what these values include. Their value statements included the most health equity markers for racialized non-dominant communities with 5 markers: culture, traditions, equity, diversity and social justice. The markers that continued to be excluded in all of the value statements are ethnicity/race, cross cultural, cultural safety; cultural humility; cultural sensitivity; cultural competency; cultural proficiency; inclusion; anti-oppression; anti-racism; racism; racialized; visible minority; hegemonic; dominant; power; and micro-aggressions. With the presence of culture, traditions, equity, diversity and social justice in the value statements, it signals that the healthcare delivery organizations have an inclination towards health equity; yet the absence of many of the terms underscores that health equity for racialized non-dominant communities is not prioritized.

Table 3

British Columbia's Healthcare Delivery Organization Summary Value Statements

\begin{tabular}{|ll|}
\hline PHSA & Respect people; be compassionate; dare to innovate; cultivate partnerships; serve with purpose \\
\hline VCHA & Service; Integrity; Sustainability \\
\hline PH & Spirituality; Integrity; Stewardship; Trust; Excellence; Respect \\
\hline VIHA & C.A.R.E.: Courage, Aspire, Respect, Empathy \\
\hline FHA & Respect, caring and trust characterize our relationships \\
\hline IHA & Quality; Integrity; Respect; Trust \\
\hline NHA & Empathy; Respect; Collaboration; Innovation \\
\hline FNHA & Respect, Discipline, Relationship, Culture, Excellence, Fairness \\
\hline
\end{tabular}

Table 3.1

Provincial Health Services Health Authority's Value Statements

\section{Respect People We treat people as individuals with unique beliefs, values, lived experiences and cultural norms. We value diversity and seek, listen to and respond to suggestions for improvement. Patients and families are at the centre of all we do.}

$\mathrm{Be}$

Compassionate

Whether it's caring for a patient, family member or colleague, being compassionate is fundamental to the work we do. We care about the health and well-being of one another and those we serve. We believe that simple acts of kindness matter.

Dare to

Innovate

As an academic health sciences organization, we achieve excellence through knowledge and innovation. We believe in daring to innovate in all areas of our work to provide the best care for patients and families. We encourage one another to be life-long learners. We learn from the experiences of patients and families and value their ideas.

Cultivate Our provincial scope means we foster partnerships wherever possible to improve health outcomes. We Partnerships collaborate with each other, those we serve and regional, provincial, national and international colleagues. We believe cultivating partnerships also means supporting patients and their families to make the healthcare decisions that are right for them.

Serve with $\quad$ Our shared drive to make meaningful improvements in care helps to guide our services. We find joy through Purpose serving others. We believe that making a profound difference in the lives of others is our legacy.

Table 3.2

Vancouver Coastal Health Authority's Value Statements

\section{Service We will provide outstanding service and respond to needs in a timely and innovative manner.}

Integrity We will serve openly and honestly in a caring and compassionate environment.

Sustainability We will focus on effectiveness, efficiency, best practices and health outcomes, holding ourselves responsible for results 
Table 3.3

Providence Health Value Statements

\begin{tabular}{|ll|}
\hline Spirituality & We nurture the God-given creativity, love and compassion that dwells within us all. \\
\hline Integrity & We build our relationships on honesty, justice and fairness \\
\hline Stewardship & We share accountability for the well-being of our community \\
\hline Trust & We behave in ways that promote safety, inclusion and support. \\
\hline Respect & We respect the diversity, dignity and interdependence of all persons \\
\hline
\end{tabular}

Table 3.4

Vancouver Interior Health Authority's Value Statements

\begin{tabular}{|ll|}
\hline Courage & To do the right thing-to change, innovate and grow. \\
\hline Aspire & To the highest degree of quality and safety. \\
\hline Respect & To value each individual and bring trust to every relationship. \\
\hline Empathy & To give the kind of care we would want for our loved ones \\
\hline
\end{tabular}

Table 3.5

Fraser Health Authority's Value Statements

Respect, caring and trust characterize our relationships

Table 3.6

Interior Health Authority's Value Statements

\begin{tabular}{|ll|}
\hline Quality & We are committed to safety and best practice. \\
\hline Integrity & We are authentic and accountable for our actions and words. \\
\hline Respect & We are courteous, \& treat each other as valued clients \& colleagues. \\
\hline Trust & We are free to express our ideas. \\
\hline
\end{tabular}

Table 3.7

Northern Health Authority's Values

\begin{tabular}{|ll|}
\hline General Statement & Value statements guide decisions and actions \\
\hline Empathy & Seeking to understand each individual's experience. \\
\hline Respect & Accepting each person as a unique individual. \\
\hline Collaboration & Working together to build partnerships. \\
\hline Innovation & Seeking creative and practical solutions. \\
\hline
\end{tabular}


Table 3.8

First Nations Health Authority's Value Statements

\begin{abstract}
Respect We believe that maintaining respectful relationships is fundamental to the achievement of our shared vision. Respectful relationships are built upon the recognition that we all have something to contribute as individuals, and participants in the First Nations health governance structure. Therefore, we commit to treating each other with dignity and generosity, being responsive to one another, and acknowledging that each entity has their own respective processes and practices. We are also committed to respectful interactions with First Nations, tripartite partners, and other collaborators.
\end{abstract}

Discipline We have the historic opportunity to achieve transformative change in First Nations health and wellness, and an obligation to make the most of this opportunity. This will require discipline amongst us, including through: loyalty to one another and our shared vision; upholding and supporting our roles, responsibilities, decisions, and processes; maintaining and nurturing unity and a united front; integrity and reliability in fulfilling our commitments, and accountability to one another for these commitments and contributions; and, solutionsoriented and active participation.

Relationships We believe that effective working relationships with First Nations, tripartite partners, and with one another are the foundation for achieving our vision and implementing our health plans and agreements. We commit to fostering effective working relationships and camaraderie underpinned by: trust; honesty; understanding; teamwork; and mutual support. We also acknowledge that humour and laughter are both good medicine, and a good way to build relationships.

Culture We are here because of those that came before us, and to work on behalf of First Nations. We draw upon the diverse and unique cultures, ceremonies, customs, and teachings of First Nations for strength, wisdom, and guidance. We uphold traditional and holistic approaches to health and self-care and strive to achieve a balance in our mental, spiritual, emotional, and physical wellness.

Excellence We are humbled and honoured to have been asked by First Nations to work on their behalf to improve health and wellness, and have a moral and personal responsibility to strive for excellence. Excellence means that our outcomes are sustainable, that our processes are professional and transparent, and that we commit to learn continuously - through capacity development opportunities, from each other and from new, different and innovative models worldwide.

Fairness

We work to improve the health and wellness of all First Nations in BC. Our decision-making reflects the best interests of all First Nations, and leads to just and equitable treatment amongst all First Nations communities, First Nations organizations, and across all regions of British Columbia. We are committed to make room for everyone, and are inclusive in our communications, information-sharing, and discussions.

\title{
Discussion
}

We are here because of those that came before us ... [we] draw upon the diverse and unique cultures, ceremonies, customs, and teachings of First Nations for strength, wisdom, and guidance ... [we] uphold traditional and holistic approaches to health and selfcare and strive to achieve a balance ... [respectful] relationships are built upon the recognition that we all have something to contribute as individuals, and participants in health governance ... we commit to treating each other with dignity and generosity, being responsive to one another ... Our decision-making reflects the best interests of all ... and leads to just and equitable treatment amongst all ... We are committed to make room for everyone, and are inclusive in our communications, information-sharing, and discussions. (First Nations Health Authority, 2018)

These excerpts from the First Nations Health Authority's value statement offer an appealing healthcare delivery narrative that is seeded with mutual respect, inclusion, safety and equity. This idealized narrative is in line with Canada's universal healthcare delivery framework, our landmark legislature and philosophical commitments; yet it too has not brought forth health equity for British Columbia's Indigenous communities signalling the ongoing disjuncture between institutional 'words' and patient 'experiences'. It is evident that 'words' can remain in a static state: where their simple existence is enacted as 'proof' that an organization is focused on specific deliverables; but the existence of 'words' can also guide an organization to perform and practice. As such, mining these institutional discourse statements reveals how organizational commitment for health equity for racialized non-dominant patients is absent or present in the institutional identity of British Columbia's health organizations.

As described above, our findings reveal that health equity for racialized non-dominant communities is not prioritized in the mission, vision or value statements that define the organizational objectives and beliefs of the healthcare delivery organizations in $\mathrm{BC}$. In answer to our first research question: "How does the public institutional discourse (located in mission statements, values and vision) include diversity and health equity for racialized non-dominant patients, families and communities?" the analysis reveals that there is limited inclusion of health equity markers. The value statements included the highest number of health equity markers $(n=5)$ which 
featured culture, traditions, equity, diversity and social justice. The vision statement analysis included one health equity marker: social justice that was taken up by only 2 of the healthcare delivery organizations. Finally, all but one of the healthcare delivery organizations had no health equity markers in their mission statements. Providence Health, the province's Catholic-based healthcare delivery organization, and the First Nations Health Authority embraced more of the health equity markers than the other healthcare delivery organizations.

Not surprisingly, institutional documents carry a performative function and discursive power that affirms organizations are indeed institutions fully equipped with institutional characteristics: such as board of directors; budgets; and mission, value and vision statements. Performing as an institution also requires that the organization is abiding by good professional practise (Strathern, 2006). As all of the healthcare delivery organizations are accountable to provincial and federal governments, these institutional documents convey that the healthcare delivery organizations are in 'order' to avoid being put in order (Strathern, 2006) and ideally building public trust - which is a significant ideal for healthcare delivery organizations. By relaying their ability to act as 'good' organizations, they 'bulletproof' themselves to deflect assessment and potential punitive measures (Strathern, 2006). In essence, organizations develop institutional armour to legitimize their professional identities and presence, and to deflect concerns of their professional services; and part of that armour is the public institutional discourse (e.g. mission, vision and value statements). In this case, B.C.'s healthcare delivery organizations perform the role of 'good' organizations - delivering universal healthcare with appropriate institutional documents and infrastructure - which diminishes the need for provincial and federal concerns. Additionally, B.C.'s Ministry of Health has not set forth recent mandates to address health in/equity for all non-dominant racialized communities but has included the necessary commitment to ensure culturally safe health services for Indigenous Peoples in the Ministry's 20182021 Service Plan. Even when direct healthcare providers feel that their organizations are not being responsive to the diverse ethnic communities they serve (Gurm \&Cheema, 2013), with institutional armour in place and no explicit provincial directives, healthcare delivery organizations are considered to be sufficiently meeting their mandates.

In our analysis, only the First Nations Health Authority stood as an exemplar of how to advocate for non-dominant communities specifically Indigenous communities. Whilst addressing health inequities for Indigenous communities is a primary goal for the First Nations Health Authority, they also operate to address historical and contemporary injustices that have given rise to systemic structures that limit the full and equitable participation and treatment of Indigenous communities in British Columbia. The First Nations Health Authority's institutional discourse offers an illustration of how to acknowledge historical and contemporary injustices and oppressions; how to include elements of cultural safety, diversity and dignity; and how to write social, political and health justice into the institutional discourse of a healthcare delivery organization. Naming oppressions and writing in what is needed offers an opportunity to shift the systemic structures away from inequitable healthcare towards equitable healthcare.

In relation to our second question: "how are inclusion and equity discourses constructed in mission statements, values and vision?" our analysis found that there is minimal acknowledgement of the health equity markers but a general sense of delivering the 'best' care for 'all' patients without consideration of equity, or the social-political-economic-historical context in which individuals and communities experience privileges or challenges/vulnerabilities. The use of subjective quality terms such as "provide superior healthcare"; "better health, best in healthcare" or "to do the right thing" are ambiguous statements (Strathern, 2006) that perform an institutional speak that says: 'we got this'; however, evidence clearly indicates that we are not providing superior, better or best healthcare to everyone. Using generic terminology provides limited information to stakeholders and provides little strategic direction (Bolan, 2005); however, when mission statements completely omit prominent issues (e.g. health equity), it clearly indicates that a particular issue is not embraced as a priority (Valsangkar, Chen, Wohltjen \& Mullan, 2014). A more recent direction for mission statements is to write for end users (i.e. patients) such that it will foster an emotional bond (David, David \& David, 2014) between healthcare delivery organizations and patients. By writing mission, vision and value statements for patients and families, healthcare delivery organizations ought to seek meaningful, critical, active and sustainable engagement with patients particularly those who experience marginalization within dominant society. Social justice and critical equity oriented perspectives affirm that marginalized voices must be brought into the center so that existing inequities are addressed and not further exacerbated.

Further, the institutional discourse statements fail to acknowledge well-substantiated social determinants of health, social determinants of inequity, or power dynamics which impact health inequities as well as other inequities (i.e. economic, employment, housing, education, etc.) (Marmot, Friel, Bell, Houweling, \& Taylor, 2008; Navarro, 2009; Raphael, 2009; Brassolotto, Raphael \& Baldeo, 2014). Health inequities that arise from social determinants of health stem from systemic, structural, societal, political and economic arrangements that position some individuals with benefits and others with vulnerabilities; these inequities challenge the ability of a

Page $12 / 18$ 
universal healthcare system to provide equitable health care when it is not designed to address systemic barriers. Not only is healthcare access and subsequently the well-being of marginalized individuals compromised, embodiment health researchers clearly identify that social, political and economic inequities biologically impact the health and well-being of racialized communities (Krieger, 2012). Due to this societal context, racialized individuals are exposed to a highly stressful environment that triggers "... pathogenic pathways, mediated by physiology, behaviour, and gene expression, that affect the development, growth, regulation, and death of our body's biological systems, organs, and cells, culminating in disease, disability, and death" (Krieger, 2012, p. 936). The harm that extends from these inequities has long-lasting repercussions on the psychological, physical, social, political and economic well-being for non-dominant racialized residents and Canadians. The absence of this paradigm: social determinants of health in the institutional discourse statements reaffirms that these types of health inequities are not conceptualized into the institutional identity framework of what healthcare delivery organizations "do" - which limits the 'institutional will' (Ahmed, 2012) to address these types of health inequities.

In answer to our final question: "what are the guiding 'truths' that inform these discourses?" we found that due to the lack of health equity markers or a health equity framework in the institutional discourse of these healthcare delivery organizations, racialized nondominant communities are constituted as "politically minor players" (Bannerji, 2000, p. 30) and subsequently marginalized from institutional objectives for equitable healthcare delivery. The conditions in which racialized non-dominant communities live are "effected by macrostructural conditions set by society, such as public policies, social values and spending" (Woolf, 2017). Health inequities for racialized non-dominant communities cannot be understood separately from the broader social-political-economichistorical context. When there is an absence of discourse regarding the social determinants of health, the 'context' in which healthcare delivery systems are operating, or health inequity for marginalized communities, healthcare delivery organizations have little organizational motivation to meet health inequities with the provision of culturally safe care.

The absence of health equity markers can be argued to result from not naming fundamental values because they are so firmly embedded in the organizational ethos and need not be named but give rise to secondary values like 'respectful care' (Giacomini, Hurley, Gold, Smith \& Abelson, 2004). While naming racism can serve as a powerful starting point to build cultural safety, advance anti-racism objectives and challenge various forms of racism from everyday microaggressions to systemic racism; omitting 'negative values language' is a well utilized strategy to focus on the positive (Giacomini, Hurley, Gold, Smith \& Abselon, 2004). For instance, utilizing 'diversity' instead of anti-racism softens the critical or accusatory nature linked to racism; hence why we evaluated an array of terms that could be critically read for the presence of health equity. But in the absence of health equity markers, we come up against silence.

Silence is no stranger to racial discourse. In Canada, we live under the ideological umbrella of democratic racism that permits and sustains two conflicting values: "[commitments to democratic principles such as justice, equality, and fairness" against "attitudes and behaviours that include negative feelings about minority groups, differential treatment, and discrimination against them" (Henry \& Tator, 1998 p. 23). Dominant communities are not typically socialized to see their own sites of privilege and the ways in which other communities experience marginalization, discrimination and oppression. Oppressed communities are not encouraged to develop a critical consciousness but to avoid "developing habits of questioning injustices" as it "maladapts people on the bottom to stay there" (Collins, 2013, p. 130). When people who experience racism break their silence - they are often penalized for speaking out; declared 'too sensitive'; or simply not believed. Particularly under the umbrella of democratic racism, we are socialized to avoid racial discussions and this silence maintains dominant privileges (DiAngelo, 2012) as well as domains of power (Collins, 2013). Further, denial strategies are deliberately utilized to silence discussions around racism and infer that racism is not a widespread, persistent phenomenon taking cultural, institutional or systemic forms but racism makes rare appearances via isolated cases (Henry \& Tator, 1998, p. 223). In lieu of these silences, healthcare delivery organizations must commit to placing these unspeakable truths on every table from policy development to direct healthcare delivery such that health equity is 'speakable' and explicitly embedded into the identity of our healthcare delivery organizations.

With Canada's commitment to universal healthcare as a "right of citizenship, not a privilege of status" (Romanow, 2002), health inequities emerging from any of the identified social determinants of health (e.g. ethnicity/race) jeopardize the foundational philosophy of Canada's universal healthcare system. British Columbia's healthcare delivery organizations serve ethnically diverse patients, families and communities - and have an increasingly ethnically diverse workforce. Systemic racism experienced by racialized non-dominant patients and or healthcare staff undermines respectful and equitable healthcare delivery and encounters. Although the HDOs acknowledge 'special populations' in their catchment communities (e.g. South Asian and Aboriginal) the analysis

Page 13/18 
presented in this paper suggests this well-intentioned acknowledgement is not followed through in ways that support the organizations to address health care inequities and provide culturally safe care.

A key component embedded in cultural safety frameworks is to actively recognize and address unequal power relations and to incorporate a "more radical, politicized understanding of cultural considerations" (Brascoupé \& Waters, 2009) as opposed to adopting culturist approaches. We recommend that the HDOs of BC (and others) review and revise their guiding documents with a lens of equity, social justice and cultural safety through a transparent process. We also recommend that ongoing education for healthcare leadership, providers and staff include a multi-tiered approach to health equity and social justice which includes but is not limited to mandatory cultural safety training, unconscious bias training and race dialogues with experienced facilitators through the lens of antiracist pedagogy (Acosta \& Ackerman-Barger, 2017). While the FNHA offers a model, such revision should not merely be a sterile manoeuver of replacing old words with new while leaving power unexamined. Rather, we suggest that such revision be undertaken with meaningful and long-term partnerships with the communities served.

This paper is an attempt to respectfully unsettle healthcare delivery organizations such that the "dynamic space of being unsettled creates space for seeing and creating alternative truths" (Collins, 2013, p 131). Our healthcare institutions are not alone in shying away from acknowledging racism and its inequitable impact on racialized non-dominant communities. In a recent report by the United Nations' Committee on the Elimination of Racial Discrimination (CERD), the CERD recognizes that Canada does not have an anti-racism strategy and has recommended the launch of a National Action Plan Against Racism as well as ensuring all provinces and territories implement anti-racism framework legislation (CERD, August 31, 2017). A national and provincial anti-racism framework, alongside actions such as collecting "reliable and comprehensive statistical data on the ethnic composition of the population including disaggregated economic and social indicators for ethnic groups, African-Canadians, Indigenous Peoples, and non-citizens" would allow for a better understanding of "the representation of minority groups in public and political life" and if these communities are accessing their "political, economic, social and cultural rights" - as well as their healthcare rights (CERD, August 31, 2017). National and provincial leadership is an essential component to directing all of our organizations, including our universal healthcare delivery organizations, towards an anti-racism and equity framework.

\section{Declarations}

\section{Ethics Approval and Consent to Participate:}

Not Applicable

\section{Consent for Publication:}

Not Applicable

\section{Availability of Data}

Data collection for this study was generated from publically accessible online sources connected to British Columbia's healthcare delivery organizations: Provincial Health Services Authority[1], Vancouver Coastal Health Authority[2], Fraser Health Authority[3], Providence Health, Vancouver Island Health Authority[4], Interior Health Authority[5] and the First Nations Health Authority. Weblinks to the data have been included throughout this article.

\section{Competing Interests}

The authors declare that they have no competing interests.

\section{Funding}

This paper is a part of a broader qualitative research study entitled: Sadhee Sehayth: Our Health Project. Sadhee Sehayth: Our Health Project is part of the first author's doctoral work. BKD received an Operating Grant from the University of British Columbia's School of Nursing to support research-associated costs.

\section{Author's Contributions}


As this was BKD's doctoral research study, she collected and analyzed the data with consultations with CV, SRK and ST. While BKD was a major contributor in writing the manuscript, CV, SRK and ST collaborated in writing this manuscript. All authors read and approved the final manuscript.

\section{Acknowledgements}

The authors acknowledge that they live, work and play on the unceded lands of the Coast Salish peoples, and are grateful for this opportunity to facilitate our work on these lands. The first author is grateful for the financial and academic support offered throughout her doctoral studies from the University of British Columbia's Interdisciplinary Studies Graduate Program (and their Fellowship); University of British Columbia's School of Nursing; Vanier Canada Graduate Scholarship; and Canadian Institutes of Health Research Doctoral Award. The authors also acknowledge the support of their academic institutions and their colleagues, communities and families for their contributions to advancing social justice and equity.

[1] http://www.phsa.ca/health-professionals/professional-resources/telehealth/using-telehealth/delivering-specialized-patientcentred-care

[2] http://www.vch.ca/Documents/Service-Plan-2015-2016-Final-October-2015.pdf

[3] http://www.fraserhealth.ca/media/201412PolicyFamilyVisitorsHospitals.pdf

[4] http://www.viha.ca/quality/care/clinical/patient/

[5] https://www.interiorhealth.ca/AboutUs/MediaCentre/NewsReleases/Documents/New\%20funding\%20to\%20help\%20create\%20teambased\%20primary\%20care\%20services\%20throughout\%20BC.pdf

\section{References}

1. Acosta D, Ackerman-Barger K. Breaking the Silence: Time to Talk About Race and Racism. Acad Med. 2017;92(3):285-8.

2. Adelson N. The Embodiment of Inequity: Health Disparities in Aboriginal Canada. Canadian Journal of Public Health / Revue Canadienne de Sante'e Publique. 2005;96:45-61.

3. Ahmed S. Embodying Diversity: Problems and Paradoxes for Black Feminists. Race Ethnicity Education. 2009;12(1):41-52.

4. Ahmed S. On Being Included: Racism and Diversity in Institutional Life. Durham; London: Duke University Press; 2012.

5. Alfred T. Colonialism and State Dependency. Journal de La Santé Autochtone. 2009;5:42-60.

6. Analoui F, Karami A. CEOs and Development of the Meaningful Mission Statement. Corporate Governance: The International Journal of Business in Society. 2002;2(3):13-20.

7. Babnik K, Breznik K, Dermol V. The Mission Statement: Organisational Culture Perspective. Industrial Management Data Systems. 2013;114(4):612-27.

8. Baetz MC, Bart CK. Developing Mission Statements Which Work. Long Range Plan. 1996;29(4):526-33.

9. Bannerji H. (2000). Dark Side of the Nation: Essays on Multiculturalism, Nationalism, and Gender (1 edition). Toronto: Canadian Scholars' Press Inc.

10. BC Ministry of Health's Setting. Priorities for BC Health Care report.

11. Bart CK, Tabone JC. Mission Statement Rationales and Organizational Alignment in the Not-For-Profit Healthcare Sector. Health Care Manage. 1998;23(4):54-69.

12. Bart CK, Hupfer M. Mission Statements in Canadian Hospitals. Journal of Health Organization Management. 2004;18(2):92110.

13. Bolan DS. (2005). Comparing Mission Statement Content in For-Profit and Not-For-Profit Hospitals: Does Mission Really Matter? Hospital Topics: Research and Perspectives on Healthcare, 83(4), 1-9.

14. Brascoupé S, Waters C. Cultural Safety: Exploring the Applicability of the Concept of Cultural Safety to Aboriginal Health and Community Wellness. Journal of Aboriginal Health. 2009;5(2):6-41. 
15. Brassolotto J, Raphael D, Baldeo N. Epistemological barriers to addressing the social determinants of health among public health professionals in Ontario, Canada: a qualitative inquiry. Critical Public Health. 2014;24(3):321-36.

16. http://doi.org/10.1080/09581596.2013.820256.

17. Browne AJ, Varcoe C. Critical cultural perspectives and health care involving Aboriginal peoples. Contemporary Nurse. 2006;22(2):155-68. http://doi.org/10.5172/conu.2006.22.2.155.

18. Bryant T, Raphael D, Shrecker T, Labonte R. Canada: A Land of Missed Opportunity for Addressing the Social Determinants of Health. Health Policy. 2011;101(1):44-58.

19. August CERD 31, 2017 Report from the CERD - International Convention on the Elimination of All Forms of Racial Discrimination: 93 Session (31 Jul 2017-25 Aug 2017) http://tbinternet.ohchr.org/_layouts/treatybodyexternal/SessionDetails1.aspx?SessionID=1110\&Lang=en.

20. Collins JC, Porras JI. Organizational Vision and Visionary Organizations. Calif Manag Rev. 1991;34(1):30-52.

21. Collins JC, Porras JI. Built to Last: Successful Habits of Visionary Companies. New York: Harper Business; 1997.

22. Collins PH. On Intellectual Activism. Philadelphia: Temple University Press; 2013.

23. Coulthard GS. Red Skin, White Masks: Rejecting the Colonial Politics of Recognition. Minneapolis: Univ Of Minnesota Press; 2014.

24. Creese G, Wiebe B. 'Survival Employment': Gender and Deskilling Among African Immigrants in Canada. International Migration. 2009;50(5):56-76.

25. CSDH. Closing the Gap in a Generation: Health Equity Through Action on the Social Determinants of Health. Final Report of the commission of Social Determinants of Health. Geneva: World Health Organization; 2008.

26. Das Gupta T. Real Nurses and Others: Racism in Nursing. Blackpoint: Fernwood Publishing; 2009.

27. David ME, David FR, David FR. Mission Statement Theory and Practice: A Content Analysis and New Direction. International Journal of Business Marketing Decision Sciences. 2014;7(1):95-110.

28. DiAngelo R. Nothing to Add: A Challenge to White Silence in Racial Discussions. Understanding Dismantling White Privilege. 2012;2(1):1-17.

29. Dua E. Exclusion through Inclusion: Female Asian migration in the making of Canada as a white settler nation. Gender Place Culture. 2007;14(4):445-66. http://doi.org/10.1080/09663690701439751.

30. Ejaz FK, Rentsch JH, Noelker LS, Castora-Binkley M. Racism Reported by Direct Care Workers in Long-Term Care Settings. Race Social Problems. 2011;3(2):92-8. http://doi.org/10.1007/s12552-011-9045-3.

31. Frohlich KL, Ross N, Richmond C. Health disparities in Canada today: Some evidence and a theoretical framework. Health Policy. 2006;79(2-3):132-43. http://doi.org/10.1016/j.healthpol.2005.12.010.

32. Giacomini M, Hurley J, Gold I, Smith P, Abselon J. The Policy Analysis of Values Talk: Lessons from Canadian Health Reform. Health Policy Journal. 2004;67:15-24.

33. Grbic D, Hafferty FW, Hafferty PK. Medical School Mission Statements as Reflections of Institutional Identity and Educational Purpose: a Network Text Analysis. Acad Med. 2013;88(6):852-60.

34. Gurm BK, Cheema J. Cultural Safety Assessment of an Urban Canadian Hospital. Journal of Cultural Diversity. 2013;20(4):17783.

35. Henry F, Tator C, Mattis W, Rees T. (1998). The Colour of Democracy: Racism in Canadian Society (2nd Edition). Scarborough, Ontario: Nelson.

36. Humphries KH, van Doorslaer E. Income-Related Health Inequality in Canada. Soc Sci Med. 2006;50(5):663-71.

37. Johnson JL, Bottorff JL, Browne AJ, Grewal S, Hilton BA, Clarke H. Othering and Being Othered in the Context of Health Care Services. Health Commun. 2004;16(2):255-71. http://doi.org/10.1207/S15327027HC1602_7.

38. Kazimi A. Undesirables: White Canada and the Komagata Maru - An Illustrated History. Vancouver: Douglas \& Mclntyre; 2012.

39. Kennedy J, Morgan S. Cost-related prescription nonadherence in the united states and Canada: A system-level comparison using the 2007 international health policy survey in seven countries. Clin Ther. 2009;31(1):213-9.

http://doi.org/10.1016/j.clinthera.2009.01.006. 
40. Khalifa AS. Mission, Purpose, and Ambition: Redefining the Mission Statement. Journal of Strategy Management. 2012;5(3):236-51.

41. Kirk G, Nolan SB. Nonprofit Mission Statement Focus and Financial Performace. Nonprofit Management Leadership. 2010;20(4):473-90.

42. Kirkham SR. The Politics of Belonging and Intercultural Health Care. West J Nurs Res. 2003;25(7):762-80. http://doi.org/10.1177/0193945903256709.

43. Krieger N. Methods for the Scientific Study of Discrimination and Health: An Ecosocial Approach. Am J Public Health. 2012;102(5):936-44. http://doi.org/10.2105/AJPH.2011.300544.

44. Lebrun LA. Effects of length of stay and language proficiency on health care experiences among Immigrants in Canada and the United States. Soc Sci Med. 2012;74(7):1062-72. http://doi.org/10.1016/j.socscimed.2011.11.031.

45. Leon M, Gabriel, Sparrow, Webb, Joe, Campbell, James, Planes, Underwood, Thomas \& McLeod, 2014.

46. Leuthesser L, Kohli C. (1997). Corporate Identity: The Role of Mission Statements. Business Horizons, May-June 1997, 59-66.

47. Lo M-CM, Bahar R. Resisting the colonization of the lifeworld? Immigrant patients' experiences with co-ethnic healthcare workers. Soc Sci Med. 2013;87:68-76. http://doi.org/10.1016/j.socscimed.2013.03.022.

48. Lukachko A, Hatzenbuehler ML, Keyes KM. Structural Racism and Myocardial Infarction in the United States. Soc Sci Med. 2014;103:42-50.

49. Maracle L. (1996). I Am Woman: A Native Perspective on Sociology and Feminism. Global Professional Publishing.

50. Marmot M, Friel S, Bell R, Houweling TA, Taylor S. Closing the gap in a generation: health equity through action on the social determinants of health. The Lancet. 2008;372(9650):1661-9. http://doi.org/10.1016/S0140-6736(08)61690-6.

51. Mikkonen J, Raphael D. Social Determinants of Health: The Canadian Facts. Toronto: York University School of Health Policy and Management; 2010. http://www.thecanadianfacts.org/.

52. Navarro V. What We Mean by Social Determinants of Health. Int J Health Serv. 2009;39(3):423-41. http://doi.org/10.2190/HS.39.3.a.

53. O'Neill JE, O'Neill DM. (2008). Health Status, Health Care and Inequality: Canada vs. the U.S. Forum for Health Economics \& Policy, 10(1). Retrieved from http://www.degruyter.com.ezproxy.library.ubc.ca/view/j/fhep.2008.10.1/fhep.2008.10.1.1094/fhep.2008.10.1.1094.xml.

54. Paradies Y, Truong M, Priest N. A Systematic Review of the Extent and Measurement of Healthcare Provider Racism. J Gen Intern Med. 2013;29(2):364-87. http://doi.org/10.1007/s11606-013-2583-1.

55. Paradies Y, Priest N, Ben J, Truong M, Gupta A, Pieterse A, Kelaher M, Gee G. Racism as a determinant of health: a protocol for conducting a systematic review and meta-analysis. Systematic Reviews. 2013;2(1):85. http://doi.org/10.1186/2046-4053-2-85.

56. Pendakur K, Pendakur R. Language as Both Human Capital and Ethnicity1. Int Migrat Rev. 2002;36(1):147-77. http://doi.org/10.1111/j.1747-7379.2002.tb00075.x.

57. Pendakur K, Pendakur R. Aboriginal Income Disparity in Canada. Can Public Policy. 2011;37(1):61-83. http://doi.org/10.3138/cpp.37.1.61.

58. Pendakur R, Bevelander P. Citizenship, Enclaves and Earnings: Comparing Two Cool Countries. Citizsh Stud. 2014;18(3-4):384407.

59. Raphael D. Escaping from the Phantom Zone: social determinants of health, public health units and public policy in Canada. Health Promotion International. 2009;24(2):193-8. http://doi.org/10.1093/heapro/dap005.

60. Ramsey PG, Miller ED. A Single Mission for Academic Medicine: Improving Health. JAMA. 2009;301(14):1475-6. doi:10.1001/jama.2009.472.

61. Reimer-Kirkham S. The Politics of Belonging and Intercultural Health Care. West J Nurs Res. 2003;25(7):762-80. https://doi.org/10.1177/0193945903256709.

62. Reimer-Kirkham S, Anderson JM. Postcolonial Nursing Scholarship: From Epistemology to Method. Adv Nurs Sci. 2002;25(1):117.

63. Romanow RJ. Building on Values: The Future of Healthcare in Canada. Ottawa: Commission on the Future of Health Care in Canada; 2002. 
64. Ross NA, Garner R, Bernier J, Feeny DH, Kaplan MS, McFarland B, Orpana HM, Oderkirk J. Trajectories of health-related quality of life by socio-economic status in a nationally representative Canadian cohort. Journal of Epidemiology of Community Health. 2012;66(7):593-8.

65. Safaei J. Income and health inequality across Canadian provinces. Health Place. 2007;13:629-38.

66. Scandura T, Gitlow A, Yau H, S.C. \& Greengarten-Jackson J. Mission Statements in Services and Industrial Corporations. International Journal of Quality Science. 1996;1(1):48-61.

67. Schoen C, Doty MM. Inequities in access to medical care in five countries: findings from the 2001 Commonwealth Fund International Health Policy Survey. Health Policy. 2004;67(3):309-22. http://doi.org/10.1016/j.healthpol.2003.09.006.

68. Schulz AJ, Israel BA, Zenk SN, Parker EA, Lichtenstein R, Shellman-Weir S, \& A.B., L. K. Psychosocial stress and social support as mediators of relationships between income, length of residence and depressive symptoms among African American women on Detroit's eastside. Soc Sci Med. 2006;62(2):510-22. http://doi.org/10.1016/j.socscimed.2005.06.028.

69. Sondik EJ, Huang DT, Klein RJ, Satcher D. Progress Toward the Healthy People 2010 Goals and Objectives. Annu Rev Public Health. 2010;31(1):271-81. http://doi.org/10.1146/annurev.publhealth.012809.103613.

70. Strathern M. (2006). Bullet Proofing: A Tale from the United Kingdom (pp. 181-205). In A. Riles's Documents: Artefacts of Modern Knowledge. University of Michigan Press: Michigan.

71. Tang SY, Browne AJ. 'Race' Matters: Racialization and Egalitarian Discourses Involving Aboriginal People in the Canadian Health Care Context. Ethnicity Health. 2008;13(2):109-27.

72. Tator C, Henry H. Racial Profiling in Canada: Challenging the Myth of a 'Few Bad Apples'. Toronto: University of Toronto Press; 2006.

73. Thobani S. (2007). Exalted Subjects: Studies in the Making of Race and Nation in Canada (1 edition). Toronto; Buffalo: University of Toronto Press, Scholarly Publishing Division.

74. Toftoy CN, Chatterjee J. Mission Statements and the Small Business. Business Strategy Review. 2004;15:41-4. doi:10.1111/j.0955-6419.2004.00326.x.

75. United Nations. (2015). Transforming the World: the 2030 Agenda for Sustainable Development. New York: United Nations: https://sustainabledevelopment.un.org/post2015/transformingourworld, accessed 5 April 2019.

76. Varcoe C. Doing Participatory Action Research in a Racist World. West J Nurs Res. 2006;28(5):525-40. http://doi.org/10.1177/0193945906287706.

77. Varcoe C, Browne AJ, Wong S, Smye VL. Harms and benefits: Collecting ethnicity data in a clinical context. Soc Sci Med. 2009;68(9):1659-66. http://doi.org/10.1016/j.socscimed.2009.02.034.

78. Valsangkar B, Chen C, Wohltjen H, Mullan F. (2014). Do Medical Schools Mission Statements Align with Nation's Health Care Needs? Academic Medicine, 89(6), 892-895.

79. $10.5402 / 2012 / 196437$

Vukic A, Jesty C, Mathews SV, Etowa J. (2012). Understanding Race and Racism in Nursing: Insights from Aboriginal Nurses. International Scholarly Research Notices, 2012, e196437. http://doi.org/10.5402/2012/196437.

80. Wallace SI. Not Fit to Stay: Public Health Panics and South Asian Exclusion. Vancouver: UBC Press; 2017.

81. Williams DR, Mohammed SA. Discrimination and racial disparities in health: evidence and needed research. J Behav Med. 2008;32(1):20-47. http://doi.org/10.1007/s10865-008-9185-0.

82. Woolf SH. Progress in Achieving Health Equity Requires Attention To Root Causes. Health Aff. 2017;36(6):984-91. 